\title{
Access to Safe Water, Sanitation, and Hygiene: A Cross-Sectional Study among the Maasai in Tanzania
}

\author{
Boniphace Jacob ${ }^{1}$ and Method Kazaura ${ }^{2 *}$ \\ ${ }^{1}$ Tanzania Field Epidemiology and Laboratory Training Program (TFELTP), Muhimbili University of Health and Allied Sciences, Dar Es Salaam, \\ Tanzania; ${ }^{2}$ Department of Epidemiology/Biostatistics, Muhimbili University of Health and Allied Sciences, Dar Es Salaam, Tanzania
}

\begin{abstract}
Safe water supply, sanitation, and hygiene (WaSH) are among key components to prevent and control waterborne diseases such as cholera, schistosomiasis, and other gastrointestinal morbidities in the community. In 2018, there was cholera outbreak in Ngorongoro district that was fueled by inadequate and unsafe water as well as poor sanitation and hygiene. We used an analytical cross-sectional study first to determine the proportion of households with access to WaSH and second to assess factors associated with coverage of household's access to WaSH. Methods included interviewing heads of the household to assess the availability of safe drinking water, use of unshared toilet/latrine by household members only, and the availability of functional handwashing facility. Eight percent of households had access to WaSH. Access to household's WaSH was positively associated with household's monthly income, education of heads of the household, and water use per person per week. To control water-related morbidities, there is a need to improve access to reliable safe drinking water, expand alternatives of households to earn more incomes, and enhance proper sanitation and hygiene services to rural areas and marginalized groups like the Maasai of Ngorongoro in Tanzania.
\end{abstract}

\section{INTRODUCTION}

Safe water supply, sanitation, and hygiene (WaSH) have a great role in public health, especially for the prevention and control of diarrheal diseases. The United Nation's sixth Sustainable Development Goal seeks to ensure availability and sustainable management of water and sanitation for all. ${ }^{1} \mathrm{Al}-$ though a big proportion of the global population has access to water, the quality of water in terms of safety is still uncertain. ${ }^{2}$ By 2017 , less than $30 \%$ of the population in sub-Saharan Africa had access to safe drinking water, less than $20 \%$ sanitation services, and less than $25 \%$ had handwashing facilities at homes. ${ }^{3}$ Erratic availability of safe drinking water leads to extended storage periods of water, and eventually, it becomes contaminated. ${ }^{4}$

Major health consequences of lack of access to adequate safe drinking water, basic sanitation, and hand hygiene are diverse, but they mainly relate to waterborne diseases. ${ }^{5-8}$ Water treatment is among major steps to enhance water quality. Household water treatment in many countries has shown some promising positive results in improving water quality and reducing the prevalence of diarrhea. ${ }^{9}$ In many of the sub-Sahara African countries, safe drinking water is generally affected by high fecal contamination because of open defection. ${ }^{10}$ In resource-limited countries, one of the easiest ways to remove contamination is water treatment by boiling and letting it cool down before storing in a clean container for subsequent use.

Tanzania experienced several cholera outbreaks since the fourth quarter of the last century. ${ }^{11}$ Among the epicenters for the cholera epidemic in Tanzania was Ngorongoro district. To respond to the outbreak, one of the interventions was to engage the community in the WaSH campaign. Throughout the campaign period, the community was sensitized on the application of safe excreta disposal, availability, and use of safe drinking water and handwashing practices. Although the

\footnotetext{
*Address correspondence to Method Kazaura, Department of Epidemiology and Biostatistics, Muhimbili University of Health and Allied Sciences, P. O. Box 65015, Dar Es Salaam, Tanzania. E-mail: methodkazaura@gmail.com
}

outbreak was controlled, it is not clear whether or not households in Ngorongoro district have consistently adhered to intervention guidelines and changed their practices to positive healthy WaSH behavior. Using a cross-sectional study, we aimed to assess coverage of household's WaSH and to examine factors associated with access to WaSH in Ngorongoro district.

\section{METHODS}

Study design and settings. The study was cross-sectional. It was conducted between March and May 2019 in four of the 10 villages of Ngorongoro district in Tanzania. The 10 villages were mostly hit with the 2018 cholera epidemic. Tribes in the area are mainly the Maasai, with few Watemi. According to the 2012 National Census, the district had a total population of about 175,000 of which $20.2 \%$ were children younger than 5 years. ${ }^{12}$ Administratively, the district has 28 wards, 42 villages, and 36,310 households. The district has inadequate supply of clean and safe water, whereby less than $40 \%$ of the population has access to clean water within a radius of $5 \mathrm{~km} .{ }^{13}$

Study population. The study population included heads of households in the targeted Maasai and Watemi villages. The two tribes constitute the majority of the Ngorongoro population in which more than $80 \%$ of the population is engaged in seminomadic and pastoral lifestyle raising cattle and goats. These tribes build their homes using clusters of cow dung that last for temporary periods. Therefore, even the standards of the toilets/latrines would match to their living homes. Culturally, the Maasai diet consists of milk and blood from their cattle. However, this way of life is slowly changing to modern settlements and sedentary lifestyle of farming. ${ }^{14}$

Sample size estimation and sampling procedure. We estimated a sample of 410 heads of the household using Kish's sample size formula for single proportion. ${ }^{15}$ The input parameters included the estimated proportion of households with sanitation facilities $(20 \%) .{ }^{16}$ This proportion was considered to yield a minimum required sample size even for other parameters, households with safe drinking water, and those with acceptable hygiene. We also used a $95 \%$ level of confidence and a $5 \%$ absolute precision. We further adjusted for 
the effect of clustering using a design effect of 1.5 and an anticipated nonresponse rate of $10 \%$. We used a two-stage cluster sampling strategy to select the study participants. In the first stage, we randomly selected four villages from a list of 10 most cholera-affected villages. Selected villages were Endulen, Esere, Kesile, and Meshili. In the second stage, we selected heads of the household using probability proportional to size cluster sampling. ${ }^{17}$

Data collection tools and procedure. We used two data collection tools, a face-to-face interview form and an observation checklist. We developed both tools guided by the objectives and experience in the field. Furthermore, before the final version of the tools, we benchmarked the developed draft tools with that of UNICEF (Core on drinking water, sanitation and hygiene for household surveys: 2018 update). ${ }^{18}$

The face-to-face interview form included information on background characteristics of heads of household, type of sources to household water, water treatment, and household's sanitation. The observation checklist included 1) access to water (type and quality of vessels to draw water for drinking), 2) household sanitation (availability of latrine facility and the distance from the main dwelling, access, users, and quality of latrine and fecal matter around the dwelling's surroundings), and 3) household hygiene (availability and quality of a handwashing facility). Initially, we developed questions for the interviews in English. The form was later translated into Kiswahili, a language widely spoken by the majority.

Data collection personnel consisted of an epidemiologist and three trained Cholera Rapid Response Team members. At least one of the team members was supposed to be fluent in Maa and Kisonjo languages in case some heads of households could not communicate well in Kiswahili. To assess the format, clarity, and order of questions, we pretested both tools in Piyaya, a village that was not earmarked for the main study. Study participants were heads of households who had stayed in the village for at least 6 months before the date of the study.

Measures. The dependent variable was access to household's WaSH. We defined a household having access to household's WaSH if it had recommended components of WaSH: 1) safe drinking water, 2) a household toilet/latrine unshared by members other household(s), and 3) a functional handwashing facility. The WHO and UNICEF developed the WaSH tool for assessing whether a water source was improved or not. ${ }^{19}$ However, the water source indicator was used to gauge water safety between different countries, rather than for intranational comparisons. ${ }^{20}$ The recommended robust and vibrant measure at microlevel was safe drinking water. ${ }^{21,22}$

To assess safe drinking water, we asked the respondent about water treatment after acquiring water from the source. A household with safe drinking water was supposed to have boiled water, added bleach/chlorine/aqua table, sieved it through a cloth or used water filter, and let it stand. We used a checklist to assess whether the household had a toilet/latrine that was unshared by members from neighboring households; a latrine had a slab, a ventilated pit latrine, flush toilet, or a composite toilet. In addition, a household was not supposed to practice open defecation. Furthermore, we used a checklist to mark the availability of a functional handwashing facility. The main independent variables included background characteristics of the respondents and of the household.

Data analysis. We summarized categorical variables using frequency tables. We assessed the association of access to household's WaSH with selected independent variables using Pearson's Chi-square test. In the multivariable analysis, we used logistic regression analysis to examine independent factors associated with access to household's WaSH. The measure of association was odds ratio. We used $95 \% \mathrm{Cls}$ to measure the strength of association. In addition, we used robust adjustment to account for clustering of the outcome within a village. The level of significance was set at $5 \%$.

Ethical consideration and permission to conduct the study. The Muhimbili University of Health and Allied Sciences Research Ethical Committee approved the study protocol (DA.287/298/01.A/08.) The regional administrative secretary, the district executive director through the district medical officer, and leaders of the selected villages granted permission to conduct the study. Participants were informed about the study and their rights to participate or to withdraw at any time during the interview process if they wished so. We maintained confidentiality and anonymity during the interviews and data analysis, respectively. All selected heads of the household signed an informed consent form or provided thumbprint as proof that they voluntarily participated in the study.

\section{RESULTS}

Description of the study participants. A total of 410 heads of the households participated in the study. Their mean age was 36.3 (SD = 10.4) years. Women headed most of the households $(307 ; 74.9 \%)$. The majority $(306 ; 74.6 \%)$ of the study participants never had formal education. The average household size was $5.6(S D=2.5)$, and the self-reported median household monthly income was TSh 55,500 (IQR = 80,000; [US\$ 24.1, SD = 34.8]) (Table 1).

Access to households' safe WaSH. Among the households, 250 (61.0\%) heads of the households reported treating water for drinking purposes. Treatment included boiling, filtering, or adding treatment chemicals. Although 349 (85.1\%) households have latrines, only 154 (37.6\%) of these latrines were improved and unshared by members of the neighboring

TABLE 1

Background characteristics of households $(n=410)$

\begin{tabular}{lc}
\hline \multicolumn{1}{c}{ Characteristic*$^{*}$} & Number (\%) \\
\hline Gender of heads of the household & $103(25.1)$ \\
Male & $307(74.9)$ \\
Female & $36.3(10.4)$ \\
Age (years), mean (SD)* & $101(28.0)$ \\
Less than 30 & $136(37.8)$ \\
30-39 & $123(34.2)$ \\
40+ & \\
Education level & $306(74.6)$ \\
Never in school & $83(20.2)$ \\
Primary (incomplete or complete) & $21(5.1)$ \\
Above primary & $5.7(2.5)$ \\
Size of household, mean (SD)* & $69(17.3)$ \\
1-3 & $285(71.3)$ \\
4-8 & $46(11.5)$ \\
$9+$ & $55,500(80,000)$ \\
Household's monthly income (TSh); & \\
median (IQR) ${ }^{\star} \dagger$ & $120(31.6)$ \\
1,000-28,000 & $132(34.7)$ \\
$28,001-85,819$ & $128(33.7)$ \\
$85,820+$ &
\end{tabular}

${ }^{*}$ Numbers do not add up to 410 because of missing responses.

†TSh 2,300 = USD 1 (year: 2019). 
households. Furthermore, households with washing facilities were 125 (30.5\%). Only 28 (6.8\%) households had handwashing facilities, water, and soap/detergent/ash on site. The overall proportion of households with access to WaSH was 32 (8.0\%) (95\% Cl: 5.6-11.1). In Figure 1, we present details of available households' WaSH components surveyed in the district.

Factors associated with access to household's safe drinking water, sanitation, and hygiene in Ngorongoro district, Tanzania. As indicated in Table 2, the level of education among the selected background characteristics for the heads of the households was positively associated with access to WaSH. Heads of the households who attained more than a primary education level had 4.2 times odds of accessing $\mathrm{WaSH}$ as compared with those never attended school (OR $=4.2,95 \% \mathrm{Cl}: 1.2-14.9)$. With respect to household's characteristics, monthly income and water per capita use were both independently and positively associated with access to WaSH. The households with a monthly average income of at least TSh 55,500 (about US\$ 24) had 14 times odds of access to WaSH as compared with households with lower monthly income (OR $=14.0,95 \% \mathrm{Cl}$ : 3.8-50.7). Similarly, the households using at least $20 \mathrm{~L}$ of water per person per day had 5.3 times odds of access to $\mathrm{WaSH}$ as compared with households using less quantity of water $(\mathrm{OR}=5.3,95 \% \mathrm{Cl}$ : 2.0-14.5).

\section{DISCUSSION}

We conducted a study in Ngorongoro district among the seminomadic and pastoralist Maasai of northern Tanzania to determine the proportion of households accessing WaSH services and to assess factors associated with access. Access to household's safe WaSH is among the important indicators that are used when controlling and protecting communities against waterborne and sanitation-related diseases such as cholera. ${ }^{23,24}$ Although there have been reports about great achievements in access to safe drinking water, improved sanitation, and hygiene facilities during the past few decades, differences in the achievements and levels of coverage between and within countries such as in rural and urban exist (UNICEF). Tanzania is not exceptional to this. ${ }^{25}$ The proportion of households accessing $\mathrm{WaSH}$ in the Ngorongoro community is only $8.0 \%$. Independent factors associated with access to $\mathrm{WaSH}$ are formal education status of heads of the households, the quantity of water use per capita per day, and average household's monthly income.

In 2018, before the cholera outbreak in Ngorongoro district, the proportion of households with access to clean water was less than $40 \%$. On the one hand, in this study, the proportion of households reporting having safe drinking water has significantly increased to more than $60 \%$. Based on our study design and possible differences of the study tools, it is difficult to ascertain this increase. On the other hand, the proportions of households having improved sanitation facilities and of those practicing open defecation are very low $(1.0 \%$ and $7.3 \%$, respectively). Globally, the majority of the rural population practice open defecation. ${ }^{26}$ Sarah and Graham ${ }^{27}$ found an association between open defecation and livestock keeping among the Ngorongoro neighbors in Kiteto. Furthermore, culturally, the Maasai do not use latrines. ${ }^{28,29}$ They even claim that they cannot construct a "house" for feces. ${ }^{30}$ Although some of the Maasai know the importance of using latrines and refraining from open defecation, many would opt to stick to their culture. In addition the Maasai like any society, changing culture may be a difficult endeavor. ${ }^{31}$

In this study, a household's monthly average income is positively associated with access to WaSH. In 2010, the WHO/ UNICEF reported a similar tendency of a positive association between household's income and access to WaSH in subSaharan Africa. ${ }^{32}$ In Abidjan, Ivory Coast, households with higher incomes were more likely to access improved water, especially during shortages, by purchasing water through alternative sources. ${ }^{33} \mathrm{~A}$ previous research in some regions of Tanzania concluded that there is a correlation between poverty and water, sanitation, and hygiene services. ${ }^{34}$ Likewise, in the current study area, access to household's WaSH is positively associated with household's monthly income. This finding may suggest that despite of cultural barriers, households with better incomes are more likely to construct their own improved latrines or toilets and have better access to safe drinking water than their counterparts.

Furthermore, formal education of heads of the households is positively associated with access to WaSH. Although studies on sociodemographic factors associated with WaSH are scanty, some reports suggest education of heads of the households is associated with separate components of WaSH like handwashing, hygiene, and water treatment. ${ }^{35-38}$ This may suggest that education is one of the fundamental elements in the process for acquiring knowledge, specifically for accessing $\mathrm{WaSH}$. Therefore, although the indigenous

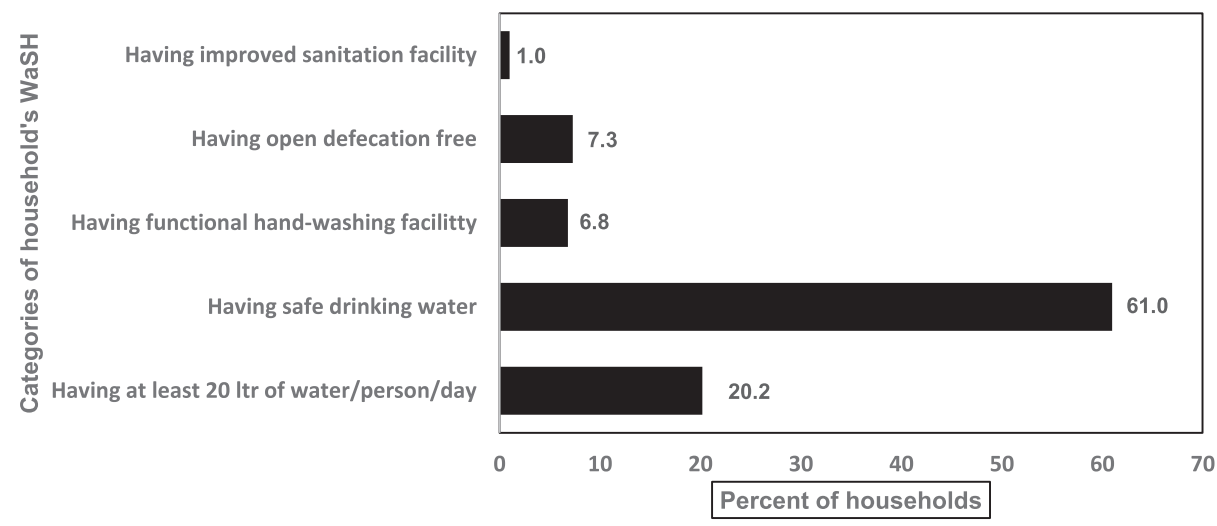

FiguRE 1. Coverage (percent) of access to household's WaSH in Ngorongoro District. 
TABLE 2

Predictors of access to household's safe drinking water, sanitation, and hygiene

\begin{tabular}{|c|c|c|c|}
\hline \multirow[b]{2}{*}{ Characteristic } & \multirow{2}{*}{$\frac{\text { Access to water supply, sanitation, and hygiene }}{\text { Number (\%) }}$} & \multicolumn{2}{|c|}{ OR $(95 \% \mathrm{Cl})^{\star}$} \\
\hline & & Unadjusted & Adjusted \\
\hline \multicolumn{4}{|l|}{ (a) For heads of the household } \\
\hline \multicolumn{4}{|c|}{ Gender of heads of the household } \\
\hline Male & $8(7.8)$ & Reference & Reference \\
\hline Female & $25(8.1)$ & $1.1(0.5,2.4)$ & $1.6(0.6,4.2)$ \\
\hline \multicolumn{4}{|l|}{ Age-group (years) } \\
\hline Less than 30 & $6(5.9)$ & Reference & Reference \\
\hline $30-39$ & $10(7.4)$ & $1.3(0.4,3.6)$ & $1.5(0.5,4.3)$ \\
\hline $40+$ & $14(11.4)$ & $2.0(0.8,5.5)$ & $2.5(0.9,7.3)$ \\
\hline \multicolumn{4}{|l|}{ Education level } \\
\hline Never attended school & $22(7.2)$ & Reference & Reference \\
\hline Primary & $6(7.2)$ & $1.0(0.4,2.6)$ & $1.5(0.5,4.0)$ \\
\hline Above primary & $5(23.8)$ & $4.0(1.4,12.0)$ & $4.2(1.2,14.9)$ \\
\hline \multicolumn{4}{|l|}{ (B) For households } \\
\hline \multicolumn{4}{|l|}{ Size of household } \\
\hline Below 6 & $15(7.0)$ & Reference & Reference \\
\hline At least 6 & $18(9.7)$ & $1.4(0.7,2.9)$ & $1.9(0.8,4.5)$ \\
\hline \multicolumn{4}{|l|}{ Monthly income } \\
\hline Below 55,500 & $4(2.1)$ & Reference & Reference \\
\hline At least 55,500 & $28(14.7)$ & $8.0(2.8,23.4)$ & $14.0(3.8,50.7)$ \\
\hline \multicolumn{4}{|c|}{ Liters of water use/person/day } \\
\hline Less than 20 & $19(6.1)$ & Reference & Reference \\
\hline At least 20 & $9(11.5)$ & $2.0(0.9,4.6)$ & $5.3(2.0,14.5)$ \\
\hline
\end{tabular}

communities in Ngorongoro have a self-perceived unique identity and authoritarian culture, one way to improve access to $\mathrm{WaSH}$ is to provide them with formal education.

In 2006, the WHO and UNICEF presented core questions on drinking water, sanitation, and hygiene potentially for use in the national household surveys. ${ }^{18}$ This tool and its update of 2018 are recommended as core household WaSH questions and indicators for use, specifically at a national level household survey. Therefore, results from this study would be underestimates as compared with results from the Joint Monitoring Programe for the national WaSH using the 2018 household WaSH indicators developed by the WHO/UNICEF.

In this study, there are several methodological limitations. First, being a cross-sectional study, it may be difficult to assess the cause and effect when determining the predictors of household's WaSH. Second, although we intensively trained interviewers, there is a possibility of respondents offering socially desirable answers causing desirability bias as a result of using interviews, rather than a self-administered tool that was not possible because of the low literacy level of study participants. Third, these data are based on self-reports. Therefore, we were not able to control the possibility of overor underestimates of household's WaSH parameters due to recall bias. Fourth, the tool that was used to assess components of household's WaSH may have not covered all predetermined possible factors. For example, we did not include cultural and traditional beliefs and social factors that may be paramount when assessing water sanitation, waste disposal, and other hygienic practices. ${ }^{39,40}$

\section{CONCLUSION}

Despite having experienced a cholera epidemic in 2018 and the intervention to improve access to $\mathrm{WaSH}$ that followed, the proportion of households accessing all components of access to safe water, sanitation, and hygiene among the indigenous community in Ngorongoro is still low. Furthermore, access to household's WaSH is associated with household's monthly income, the amount of water use per person per day, and the formal education status of the head of household. These findings suggest a need for the community and for the government leaders to expand ways for having more reliable options of accessing WaSH and to explore alternative means of earning additional income in rural areas, especially for marginalized groups like the Maasai and Watemi of Tanzania. Without these efforts, these communities will remain at a greater risk of water-related morbidities.

Received February 21, 2020. Accepted for publication December 22, 2020.

Published online March 1, 2021.

Acknowledgments: We thank the Arusha Regional Health Management Team and Ngorongoro District Medical Officer for their permission and cooperation during the study. We also thank the household heads who devoted their valuable time to participate in this study. We also extend our thanks to Nathanael Sirili who reviewed the draft of the manuscript. The American Society of Tropical Medicine and Hygiene (ASTMH) assisted with publication expenses.

Authors' addresses: Boniphace Jacob, Tanzania Field Epidemiology and Laboratory Training Program (TFELTP), Muhimbili University of Health and Allied Sciences, Dar es Salaam, Tanzania, E-mail: mhabe.bj@gmail.com. Method Kazaura, Department of Epidemiology/ Biostatistics, Muhimbili University of Health and Allied Sciences, Dar es Salaam, Tanzania, E-mail: methodkazaura@gmail.com.

\section{REFERENCES}

1. United Nations, 2015. General Assembly Resolution A/RES/70/1. Transforming Our World, the 2030 Agenda for Sustainable Development. Available at: https://www.unfpa.org/sites/ default/files/resource-pdf/Resolution_A_RES_70_1_EN.pdf. Accessed October 28, 2019.

2. Shields KF, Bain RE, Cronk R, Wright JA, Bartram J, 2015. Association of supply type with fecal contamination of source water and household stored drinking water in developing countries: a bivariate meta-analysis. Environ Health Perspect 123: 1222-1231. 
3. UNICEF, WHO, 2020. Progress on Household Drinking Water, Sanitation and Hygiene 2000-2017, 2019. Special Focus on Inequalities. New York, NY: United Nations Children's Fund (UNICEF) and World Health Organization. Accessed April 3, 2020.

4. Chalchisa D, Megersa M, Beyene A, 2017. Assessment of the quality of drinking water in storage tanks and its implication on the safety of urban water supply in developing countries. Environ Syst Res 6: 12.

5. Prüss-Ustün A, Wolf J, Bartram J, Clasen T, Cumming O, Freeman MC, Gordon B, Hunter PR, Medlicott K, Johnston R, 2019. Burden of disease from inadequate water, sanitation and hygiene for selected adverse health outcomes: an updated analysis with a focus on low- and middle-income countries. Int $J$ Hyg Environ Health 222: 765-777.

6. Null C et al., 2018. Effects of water quality, sanitation, handwashing, and nutritional interventions on diarrhoea and child growth in rural Kenya: a cluster-randomised controlled trial. Lancet Glob Health 6: e316-e329.

7. Wolf $\mathrm{J}$ et al., 2018. Impact of drinking water, sanitation and handwashing with soap on childhood diarrhoeal disease: updated meta-analysis and meta-regression. Trop Med Int Health 23: 508-525.

8. Aiello AE, Coulborn RM, Perez V, Larson EL, 2008. Effect of hand hygiene on infectious disease risk in the community setting: a meta-analysis. Am J Public Health 98: 1372-1381.

9. WHO, 2013. Household Water Treatment and Safe Storage: Manual for the Participant [Internet]. Manila, Philippines: World Health Organization Regional Office for the Western Pacific, 131. Available at: http://www.who.int/water_sanitation_health/ water-quality/household/en/. Accessed February 15, 2020.

10. Harris M, Alzua ML, Osbert N, Pickering A, 2017. Community-level sanitation coverage more strongly associated with child growth and household drinking water quality than access to a private toilet in rural Mali. Environ Sci Technol 51: 7219-7227.

11. Acosta CJ et al., 2001. Cholera outbreak in southern Tanzania: risk factors and patterns of transmission. Emerging Infect Dis 7: 583-587.

12. National Bureau of Statistics (NBS) [Tanzania] and ORC Macro, 2014. Tanzania Population and Housing Census 2012. Dar es Salaam, Tanzania.

13. Ngorongoro District Council, 2017. Promary Health Care (PHC) Report 2016/2017.

14. Løvschal M, Bøcher PK, Pilgaard J, Amoke I, Odingo A, Thuo A, Svenning JC, 2017. Fencing bodes a rapid collapse of the unique greater Mara ecosystem. Sci Rep 7: 41450.

15. Kish L, 1965. Survey Sampling. New York, NY: John Wiley \& Sons.

16. National Sanitation Management Information System (NSMIS), 2018. Sanitation and Hygiene.

17. Makela S, Si Y, Gelman A, 2018. Bayesian inference under cluster sampling with probability proportional to size. Stat Med 37: 3849-3868.

18. WHO, UNICEF, 2018. Core Questions on Drinking Water, Sanitation and Hygiene for Household Surveys: 2018 Update. New York, NY: United Nations Children's Fund (UNICEF) and World Health Organization.

19. United Nations Development Group, 2003. Indicators for Monitoring the Millennium Development Goals. New York, NY: United Nations.

20. WHO, 2010. WHO/UNICEF Joint Monitoring Programme for Water Supply and Sanitation. Progress on Sanitation and Drinking-Water: 2010 Update. Geneva, Switzerland: World Health Organization.

21. Hunter PR, MacDonald AM, Carter RC, 2010. Water supply and health. PLoS Med 7: e1000361.

22. Onda K, LoBuglio J, Bartram J, 2012. Global access to safe water: accounting for water quality and the resulting impact on MDG progress. Int J Environ Res Public Health 9: 880-894.
23. Montgomery M, Jones MW, Kabole I, Johnston R, Gordon B, 2018. No end to cholera without basic water, sanitation and hygiene. Bull World Health Organ 96: 371-371A

24. Taylor DL, Kahawita TM, Cairncross S, Ensink JH, 2015. The impact of water, sanitation and hygiene interventions to control cholera: a systematic review. PLoS One 10: e0135676.

25. Thomas J, Holbro N, Young D, 2013. A review of sanitation and hygiene in Tanzania. Research Report. London, United Kingdom: DFID. Available at: https://assets.publishing.service.gov.uk/ media/57a08a2fed915d3cfd000628/tanzania-sanitationreview.pdf. Accessed August 5, 2020.

26. Bartram J, Cairncross S, 2010. Hygiene, sanitation and water: forgotten foundations of health. PLos Med 7: 1000367-1000410.

27. Sara S, Graham J, 2014. Ending open defecation in rural Tanzania: which factors facilitate latrine adoption? Int J Environ Res Public Health 11, 9854-9870.

28. Mshida HA, Kassim N, Mpolya E, Kimanya M, 2018. Water, sanitation, and hygiene practices associated with nutritional status of under-five children in semi-pastoral communities Tanzania. Am J Trop Med Hyg 98: 1242-1249.

29. Nangawe E, 1990. Experiences from the Maasai health services project in Tanzania. Streefland $\mathrm{P}$, Chabot J, eds. Implementing primary health care; experiences since Alma-Ata. Amsterdam, The Netherlands: Royal Tropical Institute, 85-100.

30. Thitu A, Kaseje M, Augustine A, 2016. Factors Influencing Latrine Coverage Among the Maasai of Ildamat Location Kajiado District. Developing Country Studies, 22-27.

31. Kelly MP, Barker M, 2016. Why is changing health-related behaviour so difficult? Public Health 136: 109-116.

32. McMichael C, Robinson P, 2016. Drivers of sustained hygiene behaviour change: a case study from mid-western Nepal. Soc Sci Med 163: 28-36.

33. WHO/UNICEF Joint Monitoring Programme, 2010. Progress on Sanitation and Drinking Water, 2010 Update. Comparison of WASH Access Levels between the Richest and Poorest $20 \%$ of the Population.

34. Angoua ELE, Dongo K, Templeton MR, Zinsstag J, Bonfoh B, 2018. Barriers to access improved water and sanitation in poor peri-urban settlements of Abidjan, Côte d'Ivoire. PLoS One 13: e0202928

35. Kessy F, Mahali R, 2017. Water, Sanitation and Hygiene Services in Tanzania: Access, Policy Trends and Financing. THDR 2017: Background paper No. 11. ESRF Discussion paper 72. Available at: http://thdr.or.tz/docs/THDR2017BP-11.pdf. Accessed December 10, 2019

36. Schmidt WP, Aunger R, Coombes Y, Maina PM, Matiko CN, Biran A, Curtis V, 2009. Determinants of hand washing practices in Kenya: the role of media exposure, poverty and infrastructure. Trop Med Int Health 14: 1534-1541.

37. Uwimpuhwe M, Reddy P, Barratt G, Bux F, 2014. The impact of hygiene and localised treatment on the quality of drinking water in Masaka, Rwanda. J Environ Sci Health A Tox Hazard Subst Environ Eng 49: 434-440.

38. Johnson RC, Boni G, Barogui $Y$, Sopoh GE, Houndonougbo M, Anagonou E, Agossadou D, Diez G, Boko M, 2015. Assessment of water, sanitation, and hygiene practices and associated factors in a Buruli ulcer endemic district in Benin (West Africa). BMC Public Health 15: 801.

39. Routray P, Schmidt WP, Boisson S, Clasen T, Jenkins MW, 2015. Socio-cultural and behavioural factors constraining latrine adoption in rural coastal Odisha: an exploratory qualitative study. BMC Public Health 15: 880.

40. Wasonga J, Okowa M, Kioli F, 2016. Sociocultural determinants to adoption of safe water, sanitation, and hygiene practices in Nyakach, Kisumu county, Kenya: a descriptive qualitative study. J Anthropol 2016: 7434328. 